\title{
Models of embryonic diapause in Carnivora
}

\author{
BD Murphy ${ }^{1}$ and JC Fenelon ${ }^{2}$ \\ ${ }^{1}$ Centre de recherche en reproduction et fertilité, Université de Montréal, Québec, Canada \\ ${ }^{2}$ School of Biosciences, University of Melbourne, Melbourne, Australia
}

Corresponding author e-mail: bruce.d.murphy@umontreal.ca

\begin{abstract}
The phenomenon of obligate embryonic diapause, comprising developmental arrest at the blastocyst stage, has been recognized to occur in more than 60 species in three families in the Order Carnivora. The evolutionary advantage believed to be conferred by this trait is that it permits mating and parturition to occur at the most favorable times of year for reproductive success and offspring survival. The carnivore blastocyst in diapause consists of hundreds of cells, configured in the classic mammalian compartments of inner cell mass and trophoblast. It is encapsulated in a glycoprotein coat, derived, at least in part, from the zona pellucida of the parent oocyte. The temporal uncoupling of mating from parturition is regulated by changes in the annual photoperiod, mediated through the pineal gland, pars tuberalis a pars distalis of the pituitary and thyroid glands. In the best-studied species, the pituitary signal that awakes the embryo from arrest is prolactin, acting on the ovary and on the uterus. Ovarian signals, other than progesterone are not well understood, but it appears that there is an ovarian peptide essential for the reactivation of the embryo in mink. New studies have identified the uterine signals in the mink, and it has been shown that the synthesis and secretion of polyamines activates the mink embryo from diapause. While extensive progress has been made, it is not clear whether the regulatory mechanisms that have been identified in the better-known species are universal to carnivore diapause. As many of the carnivore species are endangered, further research on diapause is essential to their survival.
\end{abstract}

\section{Introduction}

Embryonic diapause is a mammalian reproductive strategy in which the fertilized egg develops to the blastocyst stage, then undergoes developmental arrest of variable, and usually speciesdependent duration [1]. It may occur in every gestation, and thus is defined as obligate, or present only under certain conditions, such as lactational stress (facultative diapause) [1]. This strategy has evolved to appear in the reproductive history of more than 130 species of mammals across multiple taxa [2]. In carnivores, diapause has been documented in the following families: Ursidae, Mustelidae, Mephididae, Odobenidae, Otariidae and Phocidae [3]. The presumed evolutionary significance of diapause is that it uncouples mating from parturition, thereby optimizing the chances for both fertilization and survival of the offspring. In carnivores, diapause is more common in higher latitude environments with greater seasonality [4] and is often closely related to patterns of seasonal breeding, with parturition occurring in the spring. Mating in late summer has been hypothesized to increaser the potential for mate selection, particularly for species with low population density [3]. Superfetation, a condition where eggs from more than one ovulation contribute to the offspring, becomes possible when the embryos from the earlier ovulations remain arrested in diapause. This permits subsequent ovulations and matings and a litter derived from 
more than one sire. Superfetation is known to occur in black bears (Ursus americanus) [5] European badgers (Meles meles) [6,7] and American mink (Neovison vison) [8]. An advantage conferred by superfetation is introduction of genetic variation by polyandry [7]. It has further been hypothesized that superfetation reduces the risk of infanticide by paternity confusion [7].

Reports on the evolution of carnivore diapause have focused on the mustelid family, where the trait is extraordinarily common, but not universal, as it is found in some 46 of 70 of species in this taxon [4]. Lindefors et al. [9] hypothesized that, since diapause is mostly present in large mustelids, it has been selected against in smaller mustelids. The alternate view, based on phylogenetic [4] and environmental considerations [3], is that latitude and seasonality are the principal evolutionary drivers for the development of the trait in mustelids. In cogent discussion, Mead [12] argued that it was unlikely that diapause evolved in mustelids due to a single factor. Phylogenetic analysis further suggests that diapause was a characteristic of gestation in an ancestral mustelid, and has been dispensed with where missing in the family Mustelidae [4]. This concept is further verified by physiological investigations that show that diapause can be induced in the European ferret (Mustela putorius furo) [10], and by the presence or absence of diapause in closely-related species such as the Eastern (Spilogale putorius) and Western (Spilogale gracilis) spotted skunks [11].

\section{Characteristics of carnivore diapause}

\section{A. The embryo in diapause species}

Blastocysts of carnivores with diapause have a certain morphological consistency, in that they have the usual Eutherian inner cell mass and trophoblast components (Fig. 1). The number of cells is substantially greater in both compartments relative to the rodent blastocyst [13]. Across the multiple taxa where it is found, there is some the variation in the cell numbers and structure of the embryo at this stage [13]. In the mink, the blastocyst of diapause is approximately $0.23 \mathrm{~mm}$ in diameter and can contain as many as 500 cells (Figure 1) [14]. Embryos in diapause in the spotted skunk are larger, 0.7-1.1 mm [15] and are comprised of a similar number of cells, with the trophoblast accounting for three fourths of the cell population [11]. The diapause blastocyst in the wolverine embryo contains $>700$ cells [16]. Carnivore blastocysts in diapause are encapsulated by a thick glycoprotein coating, approximately 5-6 $\mu \mathrm{m}$ thick in the spotted skunk embryo [11]. In most studies (e.g. in the wolverine [16]) this covering is designated the zona pellucida, but ultrastructural evaluation of the skunk blastocyst has shown that this capsule is multilayered, suggesting investment of carbohydrate during the journey of the embryo through the oviduct and uterus [17]. In a number of species, including many mustelids, several seals and the black bear, gradual increases in blastocyst diameter have been documented during diapause (see [12] for review). Mitotic activity is present in many, but not all, species during diapause [12]. Where present, it appears to be restricted to the trophoblast [12]. Following activation, the mink embryo expands rapidly, with extensive proliferation in both the trophoblast and inner cell mass [18]. Similar rapid expansion, cell proliferation and morphological modifications in both the trophoblast and inner cell mass characterize activation in the spotted skunk [15]. Less is known in other species, but rapid embryo expansion characterizes activation in the black bear [19] and the Northern fur seal [20]. 


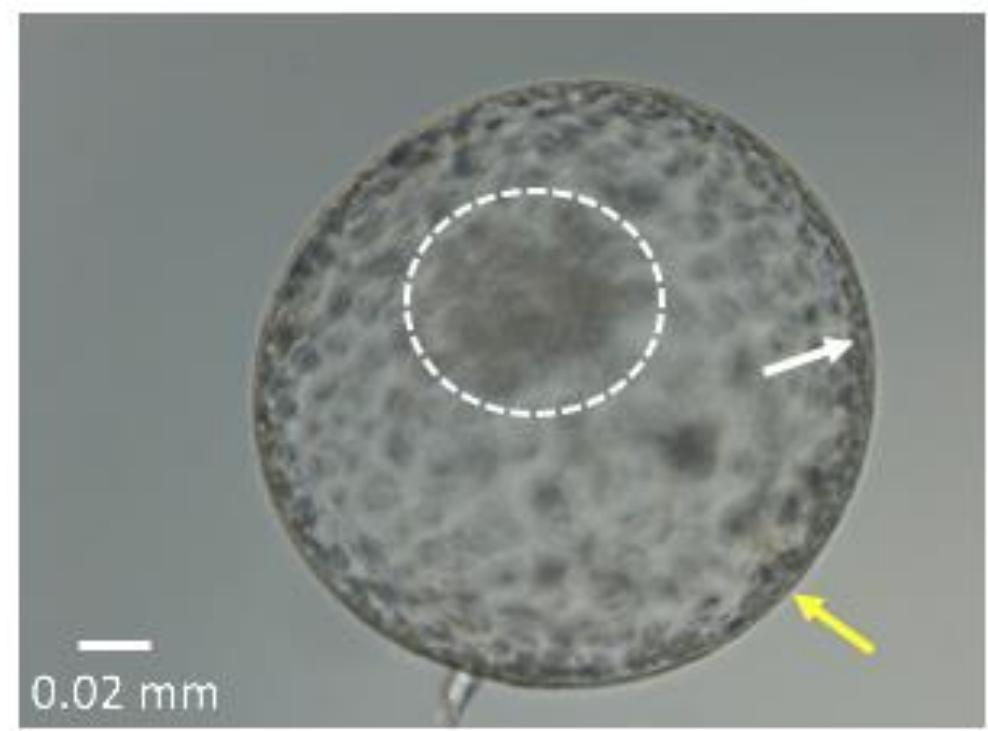

Figure 1. A mink embryo in diapause, comprising some 350 cells. The inner cell mass is circled by the dashed lines. The white arrow designates the trophoblast, while the yellow arrow points to the glycoproteinaceous capsule. Scale bar $0.2 \mathrm{~mm}$.

\section{B. Diapause in Pinnipeds}

Embryonic diapause is a characteristic of gestation in three families of aquatic mammals, the Phocidae (earless seals), the Otariidae (eared seals) and Odobenidae (walrus) [21]. The best studied in these groups is the Northern fur seal (Callorhinus ursinus), where diapause was documented as early as 1946 [22]. Females breed within a week of parturition in midsummer, and the consequent blastocyst enters a diapause that persists until early November [23]. This model is consistent with most of the Phocidae and Otariidae [24], where mating occurs soon after summer parturition and the developmentally arrested embryo does not implant and form a placenta until 25 months later, during the period of declining photoperiod. The exception may be the Weddell seal (Leptonychotes weddellii), where diapause is either quite short or, perhaps, non-existent (M. Shero personal communication).

While diapause has been designated as obligate in pinnipeds, the variable coincidence of implantation with the termination of lactation may indicate facultative influences in the form of metabolic stress modulate its length. In support of this view is the abbreviated gestation lengths in captive Australian sea lions (Neophoca cinerea), relative to less well-nourished wild counterparts [25]. Although this has been attributed to prolongation of post-implantation gestation in wild individuals, developmental arrest at this stage is rare in mammals.

Diapause appears obligate in the Pacific walrus (Odobenus rosmarus) and has been studied primarily in hunted and collected specimens [26]. Animals congregate and breed on winter feeding grounds and breed during the months of January and February [26,27]. Embryos in the blastocyst stage have been recovered in May through June, suggesting a 3-4 month diapause, in keeping with other pinniped species. The duration of gestation is 15-16 months, so that calves are born during the months of May and June in the Northern Hemisphere [26].

\section{Ursids}

The extant bears comprise eight species, with the monotypic giant panda (Ailuropoda melanoleuca) and spectacled bear (Tremarctos ornatus) and six species of the subfamily Ursinae, the polar bear 
(Ursus maritimus ), the brown bears (Ursus arctos), the black bear (Ursus americanus), the Asiatic black bear (Ursus thibetanus), the sloth bear (Ursus ursinis) and the sun bear (Ursus malayanus). While all of these species display embryonic diapause as a feature of gestation [28], in most, information is somewhat scarce, given that they are not particularly tractable experimental models. The Ursus species, best exemplified by the black bear, mate in the spring or summer, followed by a variable period (2-5 months) of diapause. Animals enter hibernation late in the fall, and, soon after, implantation occurs. Post-implantation gestation is approximately 60 days in the black bear $[29,30]$. Polar bears display similar traits, although mating occurs earlier (April-May) and implantation in October or November with a similar post-implantation gestation of 60 days [30]. It is of interest that only pregnant females den up for hibernation, while non-pregnant animals remain active through the winter [30]. The peak of brown bear estrus is in early summer [31]. Body temperature and motion sensor data from free-ranging brown bears in Sweden, were used to calculate the mean date of implantation as December 1, with parturition approximately 56 days later [5], indicating a diapause of five month duration.

Under natural conditions, the spectacled bear breeds in the Southern hemisphere summer, January and February, and births occur in the winter (June to October) outside of the tropics [32]. In North American zoos, breeding takes place in the spring, parturition in the winter. Hibernation does not occur in this species, indicating that this aspect of the annual cycle is not essential for termination of diapause.

Worldwide recognition of the endangerment of the giant panda has sparked investigation of its reproductive biology. Species scarcity has prevented extensive tissue collection or invasive investigations, and much of the available information is based on urine and fecal sampling and echographic analysis. As with other bear species, pandas mate during the spring of the year. Variation in the length of gestation, from 97-161 days [33] was an early clue to the occurrence of diapause. By combining urinary steroid analysis and topical echography, Zhang et al. [34] convincingly demonstrated that diapause was present in this species. Further urinary and fecal hormone analyses have confirmed that there is a postimplantation gestational interval of 37 days, as identified by luteal reactivation (Wauters et al. this volume).

\section{Mustelids and Mephids}

As noted above, obligate diapause is a feature of gestation in the majority of the extant species of mustelids and in at least two species of mephids. Members of these species are frequently solitary and dispersed, and are not the most amenable models for investigation. Nonetheless, considerable information has been acquired in two wild species, the Western spotted skunk and the European badger (Meles meles) [12,28]. The American mink (Neovison vison) has been farm raised for more than a century for fur, and thus, this species has been a readily available model for investigation [28]. While there are certain similarities in the reproductive strategies employed among these species, each displays distinct specializations. The Western spotted skunk displays the classic mustelid pattern, in that breeding occurs in the fall, September in this case, the blastocysts formed after approximately six days in the oviduct migrate to the uterus where they remain, unattached, for some 180-200 days [11]. This condition was characterized by Mead as a long delay [12]. The embryos then implant in April, and, after a fixed duration of postimplantation gestation, young are born in May [11]. In contrast, female mink in the Northern hemisphere remain in anestrus until approximately the winter solstice, when ovarian recrudescence is initiated, culminating in sexual receptivity early in March [28]. Following mating and a six-day period of development to the blastocyst stage, the mink embryo enters diapause for approximately three weeks [35], denoted as a short delay by Mead [12]. Implantation then ensues, and a predictable 30-day placental gestation follows [35]. In the European badger, early studies showed that the young are born in February or 
March, and that birth is followed by mating during a postpartum estrus [36]. Diapause ensues, persisting for ten months, followed by a predictable postimplantation gestation. More recent investigations have indicated that mating and consequent fertilization can occur during almost any month of the year and that diapause serves to synchronize implantation and, consequently, parturition [7].

Of the remaining 43 mustelid species in which diapause is manifest [4], much less is known. Most available information is derived from captive populations. Mead [12] catalogued mustelid species where diapause had been confirmed, with breeding and parturition dates, and the length of diapause. Within this list can be found both long and short diapause species. The circumpolar wolverine (Gulo gulo) is an example of a long diapause species, as mating occurs in May or June [12], perhaps beginning earlier and persisting for longer in captive populations [16]. New information on diapause in the form of gestational hormone profiles from fecal collections has become available on some wolverines, showing division of circannual progestin profiles into three periods: diapause, placental pregnancy and not pregnant (Batemen and Swanson abstract only). An interesting evaluation of gestation of wolverines in the wild, based on telemetric evaluation of body temperature, indicated that implantation occurred around January 1 , and parturition in late February [37].

Mead [12] has identified the striped skunk (Mephitus mephitis) as the second short delay mustelid species. Only a limited number of studies are available, as this animal is not an ideal experimental species, due to its aromatic nature. Nonetheless, Wade-Smith and Richmond [38] reported gestation length varied from 59 to 77 days, and that blastocysts were present in the uterus as late as 19 days after mating [38]. Subsequent investigation revealed distinct seasonal influence on the time of implantation and gestation, with early mating females (late February) displaying substantially longer intervals between mating and parturition than animals coupling in mid to late March [39].

\section{Regulation of diapause in carnivores}

\section{A. Photoperiod}

The annual variation in daily light-dark cycles at non-equatorial latitudes is the principal driver of seasonal events in mammals, ranging from migration to hibernation, and from pelage changes and reproductive function [40]. The temporal synchrony of implantation in individual mammalian species that share the trait of diapause strongly argues for photoperiodic regulation of both the mating process and of the termination of diapause. This is especially evident in the pinnipeds where birthing seasons are synchronized and of shorter duration in species at higher latitudes [24]. In mustelids where gestation is characterized by the long day diapause, mating takes place toward the autumnal equinox, during periods of declining day length, while implantation is triggered around the time of the vernal equinox [12]. The two known short diapause species mate in late winter, and implantation follows the onset of the spring photoperiod. The exception is the European badger, where implantation occurs during declining photoperiod, such that parturition occurs in the autumn [36].

Definitive evidence for a role of photoperiod in the regulation of diapause in species with spring implantation and parturition came from a study of captive pine martens (Martes americana), where mating was observed in late July and August, after which, females were subjected to an artificially lengthened photoperiod [41]. Diapause was abbreviated such that young were born in December, rather than the following spring. Similar treatments where photoperiod was lengthened resulted in a 2-3 month early parturition in sables (Martes zibellina) [42]. Mead 


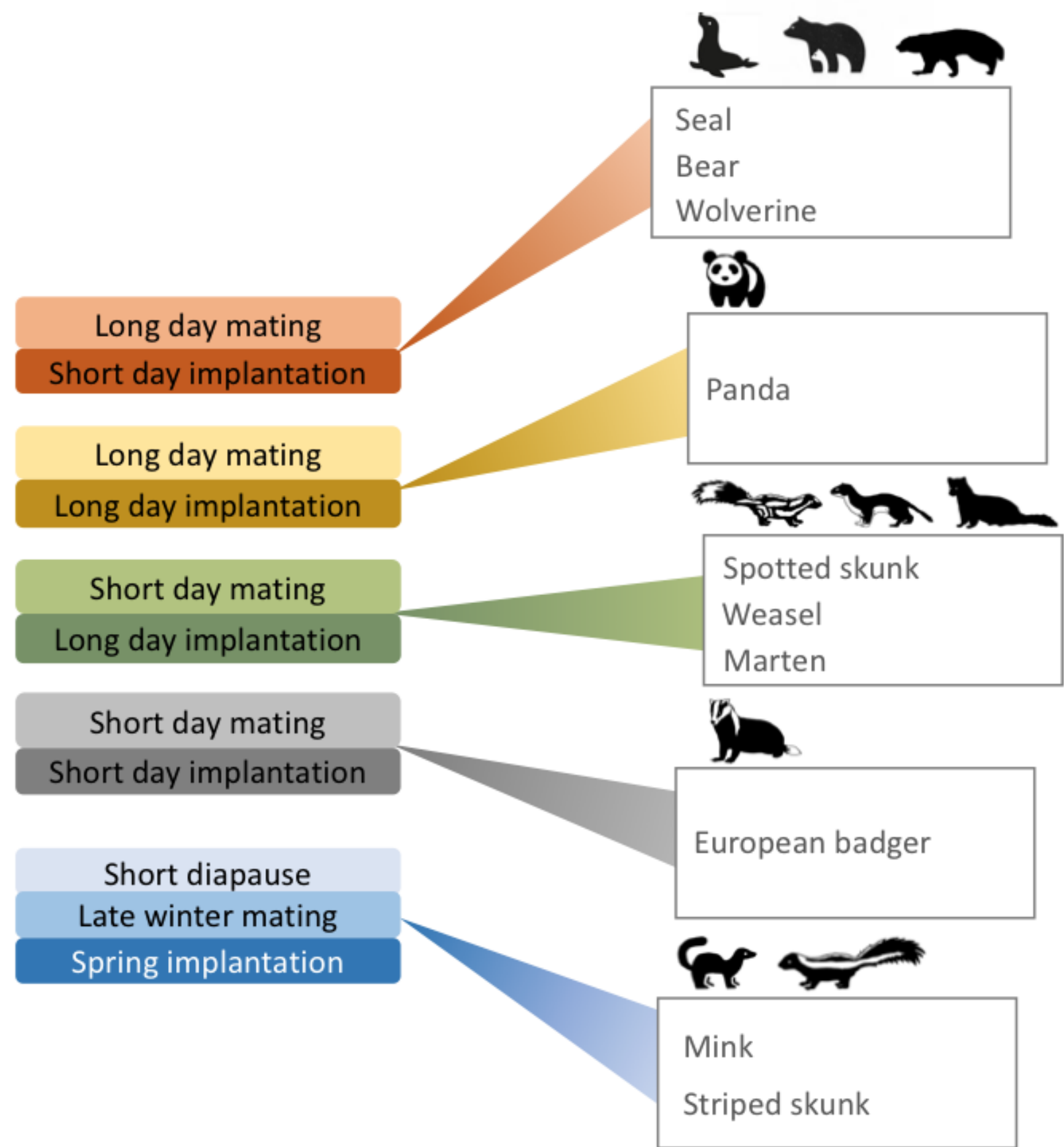

Figure 2. Carnivores display differential sensitivity to photoperiodic regimes in regulation of diapause. The most common pattern is that in which mating occurs during declining photoperiods in autumn (short day mating) and implantation in spring (long day implantation), followed by a defined period of placental gestation with young born in the late spring. There are numerous variations on the theme, which is complicated by the observation that implantion occurs during hibernation in the bears.

experimentally abbreviated diapause, and thus gestation, by some 50 days in the spotted skunk by increasing photoperiod [43]. Shortening of diapause by acceleration of photoperiod was also successful in the American mink [35]. In the European badger, where implantation is associated with short days, mimicking of winter short day photoperiods advanced implantation by four months [36]. 
Decades of research have implicated the pineal gland or epiphysis in transduction of photoperiodic information in mammals (reviewed in [40]). During the dark phase of the circadian cycle, melatonin is synthesized, primarily by the pineal (reviewed in [44]) serving as the signal to coordinate reproductive events, as exemplified by investigations in the American mink $[45,46]$. Denervation of the pineal gland eliminated the circadian pattern of melatonin in mink [45] and disrupted the timing of implantation in skunks [12] and mink [35]. Maintaining elevated melatonin in mink [47] or spotted skunks [47-49] prolonged diapause.

Two isoforms of the melatonin receptors, MT1 and MT2 have been recognized, and are widely expressed in mammals [50]. Recent transgenic mouse studies have revealed that high density MT1 expression sites have been found at a number of neuronal locations, as well as in the pars tuberalis of the hypophysis [51]. The latter site concurs with autoradiographic localization of melatonin binding in the pars tuberalis of the female spotted skunk [52] and the male mink [53], indicating a role of this organ in translating photoperiodic signals in mustelids.

\section{B. Hypophyseal regulation}

The anterior pituitary gland coordinates the endocrine cascade that regulates reproductive events in mammals. It has been shown to be an essential factor in the re-initiation of development during diapause, first shown by a report where hypophysectomy in the spotted skunk prevented implantation [54]. The first definitive identification of the pituitary regulator of diapause came from a study in which daily treatment with exogenous prolactin terminated diapause and blockade of prolactin secretion by means of a dopamine agonist prevented the re-initiation of embryogenesis in mink [55]. Subsequent studies demonstrated that, following hypophysectomy, administration of prolactin alone could induce both the reactivation of the embryo and its implantation [56]. Treatment with a dopamine antagonist to promote prolactin secretion induced precocious termination of diapause in this species [57]. In the spotted skunk, prolactin treatment beginning in mid January induced implantation 45 days prior to untreated controls [58]. In the same study, a regime of 35-day dopamine agonist treatment in early April extended diapause until after the cessation of treatment.

Further investigations revealed that melatonin suppressed the rise in prolactin that terminates diapause in both the spotted skunk [49] and the mink [47] demonstrating a mechanism for photoperiodic regulation of diapause in these two species. Hypothalamic regulation of dopamine, and thus prolactin, is centered in the arcuate nucleus [59] where it appears the melatonin receptors are absent or rare [60]. As indicated above, melatonin receptors are concentrated in the pars tuberalis of the skunk [52] and the mink [53]. Thus, it is not abundantly clear how melatonin can be regulating prolactin secretion and terminating diapause. The resolution may be found in the recent recognition of a conserved neuroendocrine pathway in vertebrate animals (Figure 3) [40]. In this model, during long days, thyrotropin secretion from the pars tuberalis results in thyroid hormone secretion [61]. This, in turn, inhibits local dopamine synthesis, thereby permitting the secretion of prolactin. The extended duration of pineal melatonin secretion during short days inhibits thyrotropin and consequently thyroxine secretion which inhibits prolactin secretion. Regulation of the termination of diapause by this mechanism requires further investigation. 


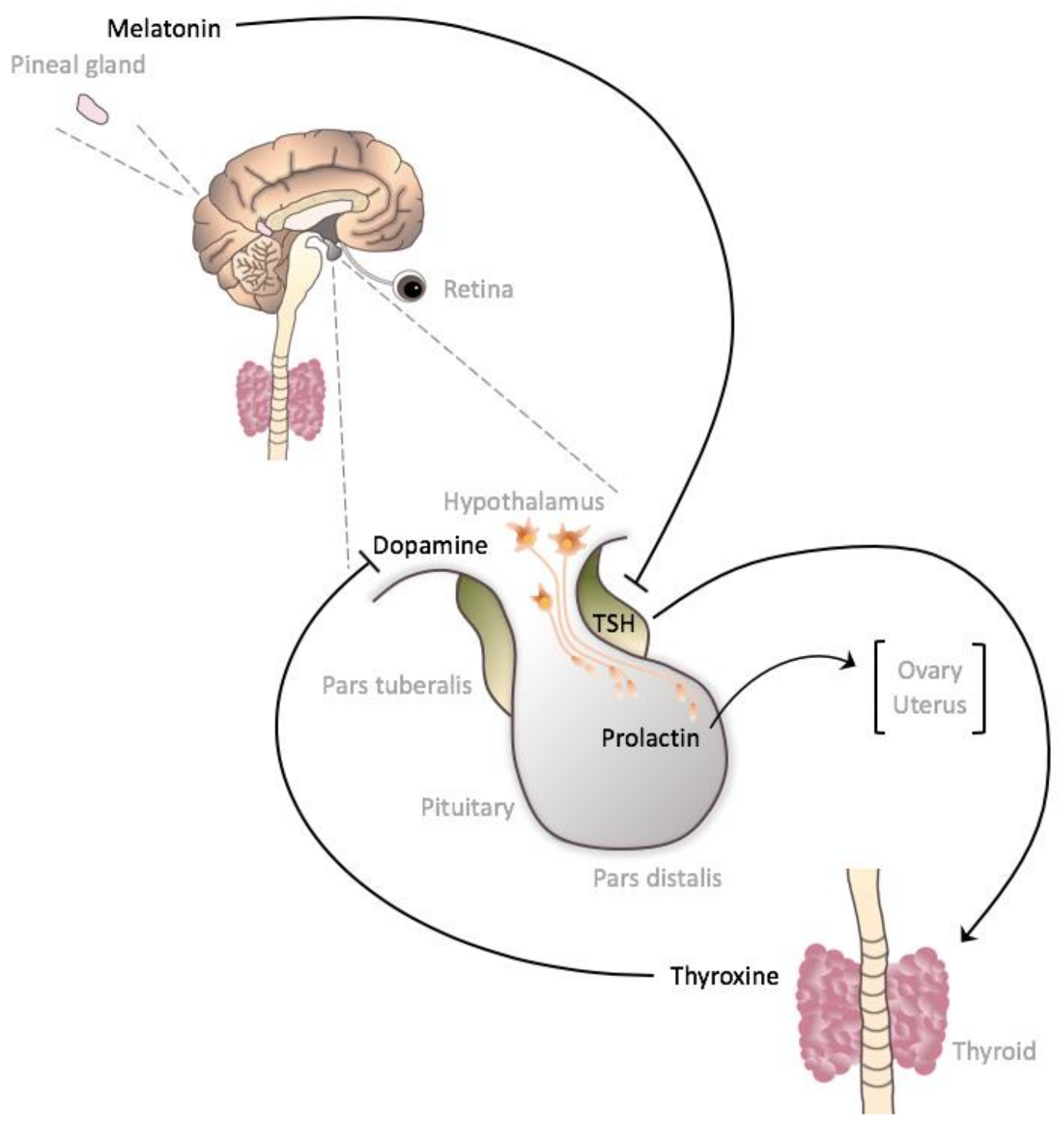

Figure 3. Mechanisms of regulation of diapause in mustelid carnivores by melatonin. The optic signal is perceived by the retina and transmitted to the pineal via the superior sympathetic ganglion. Melatonin receptors are found on the pars tuberalis of the pituitary and by acting there melatonin is hypothesized to prevent secretion of thyroid stimulating hormone (TSH). When the duration of melatonin signal is diminished by lengthening photoperiods, TSH is secreted and induces thyroxine secretion, which in turn, actis at the level of the hypothalamus to inhibit dopamine secretion into the of the pituitary. As dopamine antagonizes prolactin secretion, inhibition of its secretion permits the pituitary secretion of prolactin that then acts on the ovary and uterus to terminate embryonic diapause. This model does not explain regulatory signals where implantation occurs during a short-day photoperiod regime.

\section{Ovarian regulation}

Ovulation in mammals is followed by the formation of the corpus luteum (CL) from the components of the collapsed follicle [62]. The $\mathrm{CL}$ then becomes the source of progesterone which maintains early gestation in some species, and is required for the entirety of pregnancy in others [62]. In carnivores with diapause, corpora lutea form following ovulation, and produce low levels of progesterone, as exemplified by the mink (Figure 4) $[55,63]$ and spotted skunk $[64,65]$. The CL is reactivated and rapid increases in luteal cell size and progesterone secretion occur prior to implantation in both of these species. Progesterone in circulation or in urine or feces has been employed as a diagnostic tool to predict the timing of implantation in carnivore species as diverse as the panda and black, brown and polar bears, and wolverines and otters [66]. The patterns are 
consistent, for the most part, with the mink model of low level progesterone synthesis during diapause with several fold augmentation associated with placental gestation (reviewed in Curry et al. this volume). The European badger deviates from the model in that there is a biphasic pattern with a substantial peak during the summer, followed by a two or more month period of low levels and a reinitiation associated with termination of diapause in November [67]. The function of the first peak has not been determined, but its provenance appears to be the $\mathrm{CL}$, based on cytological evaluation.

In many species, the uterus or the utero-placental unit synthesizes progesterone and contributes to the circulating levels of this steroid. This appears not to be the case in some mustelids, as no variation in blood progesterone patterns was observed following hysterectomy in the spotted skunk [68], or the mink [47]. In contrast, hysterectomy in the European badger significantly reduces progesterone relative to intact animals [69].

In the mouse and rat, diapause can be terminated by treatment with a single administration of estrogen [2]. Implantation can be induced in ovariectomized, progesterone treated mice by the same treatment [2]. Similar treatments have been uniformly unsuccessful in terminating diapause in the spotted skunk, mink or northern fur seal [12], indicating other factors are required.

Foresman and Mead [10] demonstrated that the corpus luteum was the only compartment of the ovary required for implantation in the ferret, a species closely related to the mink that does not display diapause. Further investigation revealed that the luteal compartment was contributing a factor or factors essential for successful termination of diapause (Reviewed in [70]). Huang et al. [71] identified some proteins in the ferret $\mathrm{CL}$ as potential luteal contributors to implantation. Subsequently Schultz and Bahr [72] reported that glucose-6-phosphate isomerase was the illusive luteal factor. Confirmation of the significance of this protein in $\mathrm{CL}$ of carnivores with diapause remains to be accomplished.

Prolactin alone can induce reactivation of the $\mathrm{CL}$ in hypophysectomised mink [56] and in the intact spotted skunk [58]. Nonetheless, prolactin alone cannot maintain the $\mathrm{CL}$ in the hypophysectomized mink following implantation [56], nor maintain progesterone secretion in melatonin treated mink [47]. In many species the CL is maintained by a combination of factors known as the luteotropic complex [62]. This appears to be the case in mink, as binding and transcript abundance studies have shown that the mink CL has receptors for both prolactin [73] and luteinizing hormone (LH) [74]. Transcript studies indicated that prolactin induces its cognate receptor, as well as that for $\mathrm{LH}$ [75]. LH, but not prolactin, induces progesterone accumulation in cultures of mink luteal cells, further indicating a role for this hormone in maintaining the $\mathrm{CL}$ [63]. Together these findings indicate that prolactin is the initial factor that reactivates the $\mathrm{CL}$. It then upregulates the $\mathrm{LH}$ receptor and $\mathrm{LH}$ and serves as the luteotropic complex that maintains the $\mathrm{CL}$ of postimplantation gestation.

\section{Uterine regulation}

The proximal regulator of embryo arrest and reactivation is the uterine environment, as demonstrated by reciprocal transfer of embryos from a species displaying obligate diapause, the mink, to a species without evidence of diapause, the domestic ferret [76]. The most compelling question relative to this regulation is whether the uterine environment lacks some factor necessary for development of the embryo beyond the blastocyst stage, thus inducing diapause, or whether the uterine environment somehow inhibits further development, thus maintaining the embryo in diapause (28). A number of candidate factors related to implantation have been studied in carnivores, and variable expression may provide some clues to the paradigm of uterine regulation 


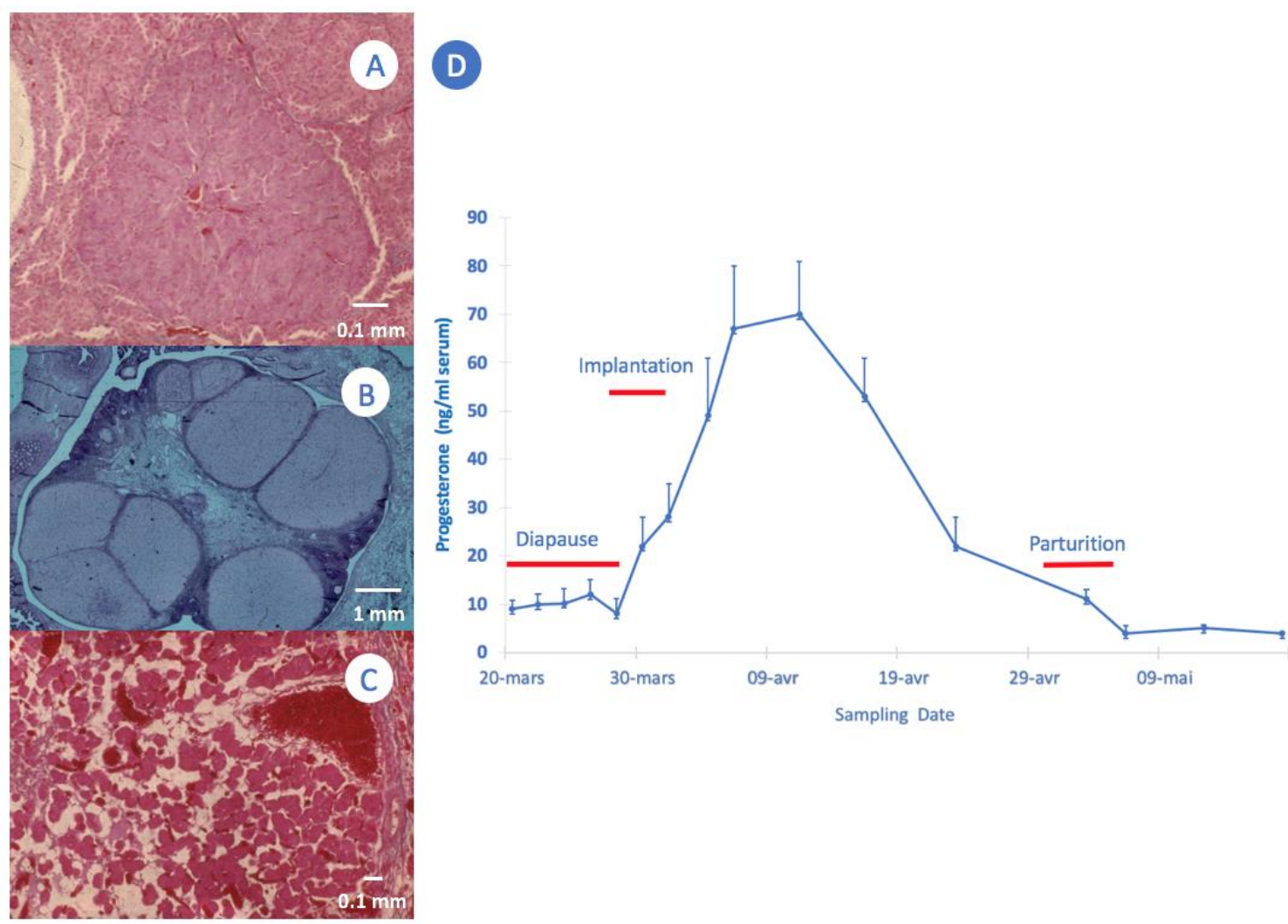

Figure 4. Luteal function during diapause and gestation in the mink. A. Corpus luteum taken during the diapause phase of pregnancy showing small, compact luteal cells Scale bar $0.1 \mathrm{~mm}$. B. Overview of an ovary following activation demonstrating the six large, active corpora lutea. Scale bar $1.0 \mathrm{~mm}$. C. Closer micrograph of a corpus luteum following activation showing enlarged luteal cells and robust vascularization. Scale bar $0.1 \mathrm{~mm}$. D. Progesterone profiles (mean \pm SEM) of six mink taken from six days following the final mating (March 20) through and after parturition.

of diapause. One of these, the cytokine, leukemia inhibitory factor (LIF), is essential for implantation in the mouse, where it can replace the nidatory estrogen surge, thereby reactivating the embryo in diapause [77]. The abundance of LIF in uterine tissue increases associated with reactivation of the embryo in the mink [78]. Likewise, the upregulation of the LIF receptor in the spotted skunk uterus appears to precede, or concurs with, activation of the embryo from diapause [79]. Thus, the availability of LIF may be a factor in terminating carnivore diapause.

Understanding uterine regulation of diapause requires a broader approach beyond candidate gene studies. In this context, global analysis of the mink uterine transcriptome has been undertaken and has revealed a large number of differentially expressed genes between diapause and reactivation $[34,80]$. Among those upregulated at activation was a cluster of genes related to the synthesis and interconversion of polyamines [28,80-83]. These studies demonstrated that polyamine synthesis may be the limiting factor that prevents development, and thus their paucity maintains the embryo in diapause (reviewed in [84]). In brief, the evidence shows that upregulation of the rate-limiting enzyme in polyamine synthesis, ornithine decarboxylase (ODC1), as well as polyamine interconversion enzymes is associated with reactivation of embryo development. Uterine concentrations of the polyamine, putrescine, are substantially greater following activation. Polyamine deprivation using the suicide inhibitor of ODC1, difluoromethylornithine (DFMO) in vivo, prevented embryo activation, while in vitro, it blocked the proliferation of both trophoblast and inner cell mass cell lines. Most telling was that evidence that when mink embryos in diapause were incubated with putrescine, they escaped from diapause and renewed development in vitro [85]. 
Together these data make a strong case for polyamines as a factor that is absent or in low abundance during diapause, but is required for activation of the blastocyst.

As noted above, secretion of prolactin is the hypophyseal factor that terminates diapause in mink [56], and prolactin activates the dormant $\mathrm{CL}$ [74]. In support of the view that prolactin may have extra-ovarian effects in regulation of diapause, Rose et al. [73] demonstrated prolactin binding sites in the mink uterus. Fenelon et al. [85] reported that the transcript for the uterine prolactin receptor was low during diapause and increased during embryo activation, while the protein is more consistently expressed during these two periods. It was then shown that the effects of prolactin on a mink uterine cell line included the rapid upregulation of the abundance of the ODC1 transcript, suggesting that there are direct effects of prolactin on the uterus associated with the termination of diapause [85].

Comparison of the uterine transcriptome of the mink during diapause with the transcriptome following reactivation with prolactin revealed 1684 differentially expressed genes [34]. In keeping with candidate gene studies, substantial increases in the abundance of both the prolactin receptor and ODC1 were detectable. Gene ontology analysis in this study revealed that the canonical intracellular pathways attributed to prolactin action, PI3K and Jak-Stat were upregulated in the uterus during reactivation of the blastocyst from diapause. These results confirm a direct and extra-ovarian role for prolactin in the termination of embryonic diapause in this carnivore. The mechanisms, beyond induction of polyamine synthesis, remain to be explored.

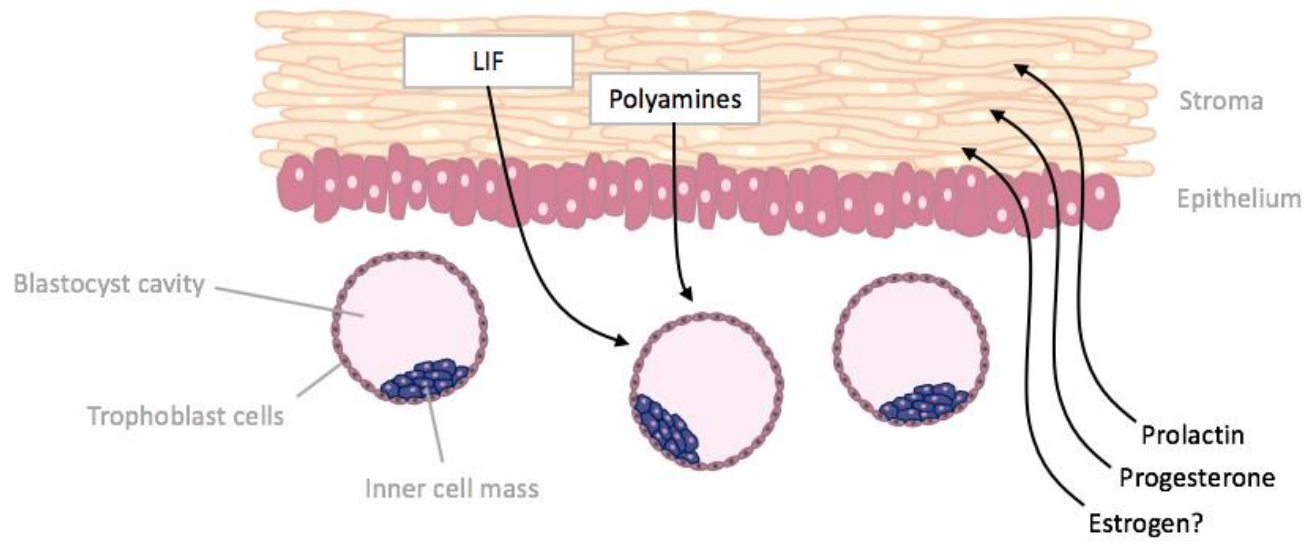

Figure 5. The uterus is the proximal site of regulation of diapause and reactivation of the carnivore embryo. In the mink model during diapause, the stimulatory signal from the pituitary in the form of prolactin is diminished. Activation of the ovary by prolactin stimulates secretion of progesterone and other elements (peptide factors) from the corpus luteum. The combination of these elements induces the synthesis and secretion of cytokines (LIF), polyamines, and growth factors from the endometrium. These then act to reactivate the blastocyst from the dormancy of diapause.

\section{Summary and questions to be resolved}

Species survival depends most critically on reproductive success, and diapause is an evolutionary strategy that has allowed carnivores to survive and thrive in non-equatorial environments. There is basic understanding of the mechanisms by which photoperiod modulates the mating and implantation in some species, but our information is fragmentary or non-existent on this regulation, particularly in aquatic species. Some of the complexity of pituitary reactivation of the $\mathrm{CL}$ to terminate diapause by prolactin has been worked out, but only in a single species, and it is not known whether these mechanisms are universal in carnivores. The circumstantial evidence that polyamine synthetic enzyme expression in the mink uterus correlates with activation of the blastocyst from diapause has been reinforced by the finding that one polyamine, putrescine can 

96

induce that activation in vitro. While this indicates that the uterine environment lacks at least one factor necessary for the continuation of development, the regulatory system is surely more complex and the signals may vary between species. Modern technology, in particular, global and systems approaches provide the potential to unravel the mysteries of diapause at the neural, hypophyseal, ovarian, uterine and embryonic level.

\section{Declaration of interest}

The authors declare that there is no conflict of interest that could be perceived as prejudicing the impartiality of this article'

\section{Acknowledgements}

Experiments from the Murphy laboratory were made possible by the generous and continual support of the Natural Sciences and Engineering Research Council of Canada. The figures were prepared by the Vickie Roussel who also contributed extensive technical assistance in aid of the investigations.

\section{References}

[1] Renfree MB, Fenelon JC. 2017 The enigma of embryonic diapause. Development 144(18) 3199-3210.

[2] Fenelon JC, Banerjee A and Murphy BD. 2014 Embryonic diapause: development on hold. Int J Dev Biol 58(2-4) 163-174.

[3] Ferguson SH, Higdon JW and Larivière S. 2006 Does seasonality explain the evolution and maintenance of delayed implantation in the family Mustelidae (Mammalia: Carnivora)? Oikos 114 249-256.

[4] Thom MD, Johnson DD and MacDonald DW. 2004 The evolution and maintenance of delayed implantation in the mustelidae (mammalia: carnivora). Evolution 58(1) 175-183.

[5] Himelright BM, Moore JM, Gonzales RL, Mendoza AV, Dye PS, Schuett RJ, Durrant BS, Read BA and Spady TJ. 2014 Sequential ovulation and fertility of polyoestrus in American black bears (Ursus americanus). Conserv Physiol 2(1) cou051.

[6] Corner LA, Stuart L, Kelly DJ and Marples NM. 2015 Reproductive Biology Including Evidence for Superfetation in the European Badger Meles meles (Carnivora: Mustelidae). PLoS One 10(10) e0138093.

[7] Yamaguchi N, Dugdale HL and Macdonald DW. 2006 Female receptivity, embryonic diapause, and superfetation in the European badger (Meles meles): implications for the reproductive tactics of males and females. Q Rev Biol 81(1) 33-48.

[8] Enders RK. 1952 Reproduction in the mink. Proc Am Phil Soc 96 691-7559414481.

[9] Lindenfors P, Dalen L and Angerbjorn A. 2003 The monophyletic origin of delayed implantation in carnivores and its implications. Evolution 57(8) 1952-1956.

[10] Foresman KR and Mead RA. 1978 Luteal control of nidation in the Ferret (Mustela putorius). Biol Reprod 18(3) 490-496.

[11] Mead RA. 1968 Reproduction in western forms of the spotted skunk (genus Spilogale). J Mammal 49(3) 373-390.

[12] Mead RA. 1989 The physiology and evolution of delayed implantation in carnivores. In: Gittleman JL, ed. Carnivore behaviour, ecology and evolution. Springer US; Chapter 16, 437-464.

[13] Lopes FL, Desmarais JÁ and Murphy BD. 2004 Embryonic diapause and its regulation. Reproduction 128(6) 669-678.

[14] Fenelon JC and Murphy BD. 2019 Culture of Mink Preimplantation Embryos. Methods Mol Biol 2006 269-277. 
[15] Enders AC, Schlafke S, Hubbard NE and Mead RA. 1986 Morphological changes in the blastocyst of the western spotted skunk during activation from delayed implantation. Biol Reprod 34(2) 423-437.

[16] Wright PL and Rausch RL. 1955 Reproduction in the wolverine, I. J Mammol 36 346-355.

[17] Enders AC and Mead RA. 1996 Progression of trophoblast into the endometrium during implantation in the western spotted skunk. Anat Rec 244(3) 297-315.

[18] Desmarais JA, Bordignon V, Lopes FL, Smith LC and Murphy BD. 2004 The escape of the mink embryo from obligate diapause. Biol Reprod 70(3) 662-670.

[19] Wimsatt WA. 1963 Delayed implantation in the Ursidae, with particular reference to the black bear (Ursus americanus Pallas). In: Enders AC, ed. Delayed Implantation. Univ. Chicago Press 49-76.

[20] Daniel JC, Jr. 1971 Growth of the preimplantation embryo of the northern fur seal and its correlation with changes in uterine protein. Dev Biol 26(2) 316-322.

[21] Pomeroy P. 2011 Reproductive cycles of marine mammals. Anim Reprod Sci 124(3-4) 184-193.

[22] Enders RK, Pearson OP and Pearson AK. 1946 Certain aspects of reproduction in the fur seal. Anat Rec 94 213-227.

[23] Shero MR, Bergfelt DR, Testa JW and Adams GP. 2018 Pairing ultrasonography with endocrinology to elucidate underlying mechanisms of successful pregnancy in the northern fur seal (Callorhinus ursinus). Gen Comp Endocrinol 255 78-89.

[24] Atkinson S. 1997 Reproductive biology of seals. Rev Reprod 2(3) 175-194.

[25] Gales NJ, Williamson P, Higgins LV, Blackberry MA and James I. 1997 Evidence for a prolonged postimplantation period in the Australian sea lion (Neophoca cinerea). J Reprod Fertil 111(2) 159-163.

[26] Fay FH. 1982 Ecology and biology of the Pacific walrus, Odobenus rosmarus divergens Illiger. Washington DC: United States Department of the Interior, Fish and Wildlife Service 1-279.

[27] Sandell M. 1990 The evolution of seasonal delayed implantation. Q Rev Biol 65(1) 23-42.

[28] Fenelon JC, Lefevre PL, Banerjee A and Murphy BD. 2017 Regulation of diapause in carnivores. Reprod Domest Anim 52 Suppl 2 12-17.

[29] Schulz LC, Nelson RA, Pyter LM and Bahr JM. 2003 Induction of pseudopregnancy in the American Black Bear (Ursus americanus). J Exp Zool A Comp Exp Biol 298(2) 162-166.

[30] Palmer SS, Nelson RA, Ramsay MA, Stirling I and Bahr JM. 1988 Annual changes in serum sex steroids in male and female black (Ursus americanus) and polar (Ursus maritimus) bears. Biol Reprod 38(5) 10441050.

[31] Spady TJ, Lindburg DG and Durrant BS. 2007 Evolution of reproductive seasonality in bears. Mammal Review 21-53.

[32] Appleton RD, Van Horn RC, Noyce KV, Spady TJ, Staisgood RR and Arcese P. 2018 Phenotypic plasticity in the timing of reproduction in Andean bears. J. Zool 305 196-202.

[33] Monfort SL, Dahl KD, Czekala NM, Stevens L, Bush M and Wildt DE. 1989 Monitoring ovarian function and pregnancy in the giant panda (Ailuropoda melanoleuca) by evaluating urinary bioactive FSH and steroid metabolites. J Reprod Fertil 85(1) 203-212.

[34] Cao X, Zhao J, Liu Y, Ba H, Wei H, Zhang Y, Wang G, Murphy BD and Xing X. 2019 Transcriptome Changes in the Mink Uterus during Blastocyst Dormancy and Reactivation. Int J Mol Sci 20(9).

[35] Murphy BD and James DA. 1974 The effects of light and sympathetic innervation to the head on nidation in mink. J Exp Zool 187(2) 267-276.

[36] Canivenc R and Bonnin M. 1979 Delayed implantation is under environmental control in the badger (Meles meles L.). Nature 278(5707) 849-850.

[37] Thiel A, Evans AL, Fuchs B, Arnemo JM, Aronsson M and Persson J. 2019 Effects of reproduction and environmental factors on body temperature and activity patterns of wolverines. Front Zool 1621.

[38] Wade-Smith J and Richmond ME. 1978 Induced ovulation, development of the corpus luteum, and tubal transport in the striped skunk (Mephitis mephitis). Am J Anat 153(1) 123-141.

[39] Wade-Smith J, Richmond ME, Mead RA and Taylor H. 1980 Hormonal and gestational evidence for delayed implantation in the striped skunk, Mephitis mephitis. Gen Comp Endocrinol 42(4) 509-515. 
[40] Dardente H, Wood S, Ebling F, Saenz de Miera C. 2019 An integrative view of mammalian seasonal neuroendocrinology. J Neuroendocrinol 31(5) e12729.

[41] Pearson OP and Enders RK. 1944 Duration of pregnancy in certain mustelids. J Exp Zool 95 21-35.

[42] Beliaev DK, Perel'Dik NS and Portnova NT. 1951 [Experimental reduction of the embryonal development period of sables Martes zibellina L]. Zh Obshch Biol 12(4) 260-265.

[43] Mead RA.1971 Effects of light and blinding upon delayed implantation in the spotted skunk. Biol Reprod 5(2) 214-220.

[44] Hazlerigg D and Loudon A. 2008 New insights into ancient seasonal life timers. Curr Biol 18(17) R795R804.

[45] Ravault JP, Martinet L, Bonnefond C, Claustrat B and Brun J. 1986 Diurnal variations of plasma melatonin concentrations in pregnant or pseudopregnant mink (Mustela vison) maintained under different photoperiods. J Pineal Res 3(4) 365-373.

[46] Tillet $Y$, Meusy-Dessolle $N$ and Martinet L. 1989 Immunohistochemical demonstration and radioimmunoassay of melatonin in the mink pineal gland. Cell Tissue Res 257(1) 23-28.

[47] Murphy BD, DiGregorio GB, Douglas DA and Gonzalez-Reyna A. 1990 Interactions between melatonin and prolactin during gestation in mink (Mustela vison). J Reprod Fertil 89(2) 423-429.

[48] May R and Mead RA. 1986 Evidence for pineal involvement in timing implantation in the western spotted skunk. J Pineal Res 3(1) 1-8.

[49] Kaplan JB, Berria M and Mead RA. 1991 Prolactin levels in the western spotted skunk: changes during pre- and periimplantation and effects of melatonin and lesions to the anterior hypothalamus. Biol Reprod 44(6) 991-997.

[50] Pevet P, Klosen P and Felder-Schmittbuhl MP. 2017 The hormone melatonin: Animal studies. Best Pract Res Clin Endocrinol Metab 31(6) 547-559.

[51] Adamah-Biassi EB, Zhang Y, Jung H, Vissapragada S, Miller RJ and Dubocovich M. 2014 Distribution of MT1 melatonin receptor promoter-driven RFP expression in the brains of BAC C3H/HeN transgenic mice. J Histochem Cytochem 62(1) 70-84.

[52] Duncan MJ and Mead RA. 1992 Autoradiographic localization of binding sites for 2-

[125I]iodomelatonin in the pars tuberalis of the western spotted skunk (Spilogale putorius latifrons). Brain Res 569(1) 152-155.

[53] Boissin-Agasse L, Barberis C, Audigier S, Roch G and Boissin J. 1992 Localization of melatonin binding sites in the pars tuberalis of the mink at three times during the seasonal testicular cycle. Neurosci Lett 144(12) $147-151$.

[54] Mead RA. 1975 Effects of hypophysectomy on plastocyst survival, progesterone secretion and nidation in the spotted skunk. Biol Reprod 12(4) 526-533.

[55] Papke RL, Concannon PW, Travis HF and Hansel W. 1980 Control of luteal function and implantation in the mink by prolactin. J Anim Sci 50(6) 1102-1107.

[56] Murphy BD, Concannon PW, Travis HF and Hansel W. 1981 Prolactin: the hypophyseal factor that terminates embryonic diapause in mink. Biol Reprod 25(3) 487-491.

[57] Murphy BD.1983 Precocious induction of luteal activation and termination of delayed implantation in mink with the dopamine antagonist pimozide. Biol Reprod 29(3) 658-662.

[58] Berria M, Joseph MM and Mead RA. 1989 Role of prolactin and luteinizing hormone in regulating timing of implantation in the spotted skunk. Biol Reprod 40(2) 232-238.

[59] Crowley WR. 2015 Neuroendocrine regulation of lactation and milk production. Compr Physiol 5(1) 255-291.

[60] Li Q, Rao A, Pereira A, Clarke IJ and Smith JT. 2011 Kisspeptin cells in the ovine arcuate nucleus express prolactin receptor but not melatonin receptor. J Neuroendocrinol 23(10) 871-882.

[61] Lomet D, Cognie J, Chesneau D, Dubois E, Hazlerigg D and Dardente H. 2018 The impact of thyroid hormone in seasonal breeding has a restricted transcriptional signature. Cell Mol Life Sci 75(5) 905-919.

[62] Murphy BD. 2000 Models of luteinization. Biol Reprod 63(1) 2-11. 
[63] Douglas DA, Song JH, Moreau GM and Murphy BD. 1998 Differentiation of the corpus luteum of the mink (Mustela vison): mitogenic and steroidogenic potential of luteal cells from embryonic diapause and postimplantation gestation. Biol Reprod 58(5) 1163-1169.

[64] Mead RA and Eik-nes KB. 1969 Seasonal variation in plasma levels progesterone in western forms of the spotted skink. J Reprod Fert Suppl. 6 397-403.

[65] Sinha AA and Mead RA. 1975 Ultrastructural changes in granulosa lutein cells and progesterone levels during preimplantation, implatation, and early placentation in the western spotted skunk. Cell Tissue Res 164(2) 179-192.

[66] Larson S, Casson CJ and Wasser S. 2003 Noninvasive reproductive steroid hormone estimates from fecal samples of captive female sea otters (Enhydra lutris). Gen Comp Endocrinol 134(1) 18-25.

[67] Bonnin M, Canivenc R and Ribes C. 1978 Plasma progesterone levels during delayed implantation in the European badger (Meles meles). J Reprod Fertil 52(1) 55-58.

[68] Mead RA and Swannack A. 1978 Effects of hysterectomy on luteal function in the western spotted skunk (Spilogale putorius latifrons). Biol Reprod 18(3) 379-383.

[69] Bonnin M, Canivenc R and Charron G. 1981 [Changes in plasma progesterone levels in the female badger after removal of the pregnant uterus]. C R Seances Acad Sci III 293(2) 143-145.

[70] Mead RA. 1986 Role of the corpus luteum in controlling implantation in mustelid carnivores. Ann $N Y$ Acad Sci 476 25-35.

[71] Huang JL, Powell M and Mead RA. 1993 Luteal protein secretion during preimplantation in the ferret. Biol Reprod 48(3) 647-654.

[72] Schulz LC and Bahr JM. 2003 Glucose-6-phosphate isomerase is necessary for embryo implantation in the domestic ferret. Proc Natl Acad Sci U S A 100(14) 8561-8566.

[73] Rose J, Stormshak F, Adair J and Oldfield JE. 1983 Prolactin binding sites in the uterus of the mink. Mol Cell Endocrinol 31(1) 131-139.

[74] Douglas DA, Houde A, Song JH, Farookhi R, Concannon PW and Murphy BD. 1998 Luteotropic hormone receptors in the ovary of the mink (Mustela vison) during delayed implantation and earlypostimplantation gestation. Biol Reprod 59(3) 571-578.

[75] Douglas DA, Song JH, Houde A, Cooke GM and Murphy BD. 1997 Luteal and placental characteristics of carnivore gestation: expression of genes for luteotrophic receptors and steroidogenic enzymes. J Reprod Fertil Suppl 51 153-166.

[76] Chang MC. 1968 Reciprocal insemination and egg transfer between ferrets and mink. J Exp Zool 168(1) 49-59.

[77] Rosario GX and Stewart CL. 2016 The Multifaceted Actions of Leukaemia Inhibitory Factor in Mediating Uterine Receptivity and Embryo Implantation. Am J Reprod Immunol 75(3) 246-255.

[78] Song JH, Houde A and Murphy BD. 1998 Cloning of leukemia inhibitory factor (LIF) and its expression in the uterus during embryonic diapause and implantation in the mink (Mustela vison). Mol Reprod Dev 51(1) 13-21.

[79] Passavant C, Zhao X, Das SK, Dey SK and Mead RA. 2000 Changes in uterine expression of leukemia inhibitory factor receptor gene during pregnancy and its up-regulation by prolactin in the western spotted skunk. Biol Reprod 63(1) 301-307.

[80] Lefevre PL, Palin MF, Beaudry D, Dobias-Goff M, Desmarais JA, Llerena VE and Murphy BD. 2011 Uterine signaling at the emergence of the embryo from obligate diapause. Am J Physiol Endocrinol Metab 300(5) E800-808.

[81] Fenelon JC, Shaw G, Frankenberg SR, Murphy BD and Renfree MB. 2017 Embryo arrest and reactivation: potential candidates controlling embryonic diapause in the tammar wallaby and mink. Biol Reprod 96(4) 877-894.

[82] Lefevre PL, Palin MF, Chen G, Turecki G and Murphy BD. 2011 Polyamines are implicated in the emergence of the embryo from obligate diapause. Endocrinology 152(4) 1627-1639.

[83] Lefevre PL, Palin MF and Murphy BD. 2011 Polyamines on the reproductive landscape. Endocr Rev 32(5) 694-712. 
[84] Fenelon JC and Murphy BD. 2018 New functions for old factors: the role of polyamines during the establishment of pregnancy. Reprod Fertil Dev 31(7) 1228-1239.

[85] Fenelon JC, Banerjee A, Lefevre P, Gratian F and Murphy BD. 2016 Polyamine-mediated effects of prolactin dictate emergence from mink obligate embryonic diapause. Biol Reprod 95(1) 6.

\section{Audience Discussion}

Barbara Drews: Do you have any idea whether prolactin stimulation would induce the same differential gene expression in a non-pregnant animal? Maybe some of the gene expression changes we see are just in fact related to implantation, not necessarily with the termination of diapause.

Bruce Murphy: That's a difficult question to answer, because we've not looked at non-pregnant animals to see what prolactin does, although some of the work of the early recognition of the presence of the prolactin receptor showed that it is expressed in the uterus of animals at the time of what we call pelting, which is way back in the when the animals are reproductively quiescent. So the prolactin receptor is expressed, but what the downstream effects of this expression might be are unknown.

Marilyn Renfree: I'm interested in your comments on the capsule. You said it was three layered and Alan had it as a zona pellucida, but if it's a three-layered capsule, that's exactly what the shell is in marsupials. It is deposited as it comes down the oviduct and into the cranial part of the uterus and it gets thicker as it goes down the oviduct and by then it's really tough. As the blastocyst expands into a vesicle it attenuates and it really increases in its surface area by many hundreds of times. Is the mink capsule like a horse capsule? The horse capsule is very like the wallaby or the marsupial shell. It's not quite the same, but very similar.

Bruce Murphy: That information actually comes from Alan Enders' electron micoscopy of the blastocyst and he shows it is trilaminar. That is what was a surprise that he called it a zona pellucida instead of a capsule. In the horse, the capsule had been proposed to $b$ trophoblastic in origin. When collect mink morulae from the oviduct and culture them to blastocyst in vitro, there does not appear to be a capsule, only the zona pellucida. suggesting provenence from the oviduct/uterus. Further research is necessary to clarify this issue.

The idea would be perhaps to collect at different stages of development in the oviduct and then observe by electron microscopy.

Unknown questioner: I think the horse capsule is at least partly deposited by the trophoblast as well.

Marilyn Renfree: But some of it comes from the outside too.

Bruce Murphy: But this is clearly the zona, with other material presumably added following ovulation.

Jane Fenelon: I was just going to add, because we'll talk about this tomorrow, but when the mink blastocyst shrinks in vitro, it clearly looks more like the shell in wallaby, but they they don 't have the mucin layer- there is this shell coat and then the zona shrinks. So it's definitely like an extracellular layer.

Marilyn Renfree: We should follow it up, it might be yet another common characteristic. 